\title{
Macroscopic Findings Sequence Number
}

National Cancer Institute

\section{Source}

National Cancer Institute. Macroscopic Findings Sequence Number. NCI Thesaurus.

Code C119867.

An identifier that describes the relative position of macroscopic findings data within a series. 